\title{
Ellis-van Creveld Syndrome: A Rare Clinical Report of Oral Rehabilitation by Interdisciplinary Approach
}

\author{
Talib Amin Naqash $\left(\mathbb{D},{ }^{1}\right.$ Ibrahim Alshahrani $\mathbb{D D}^{2}$, and Siripan Simasetha ${ }^{3}$ \\ ${ }^{1}$ Department of Prosthetic Dentistry, King Khalid University College of Dentistry, Abha, Saudi Arabia \\ ${ }^{2}$ Department of Pediatric Dentistry and Orthodontic Sciences, King Khalid University College of Dentistry, Abha, Saudi Arabia \\ ${ }^{3}$ Dental Department, Bhumibol Adulyadej Hospital, The Royal Thai Air Force, Bangkok, Thailand
}

Correspondence should be addressed to Talib Amin Naqash; go4talib@yahoo.com

Received 28 October 2017; Accepted 29 November 2017; Published 23 January 2018

Academic Editor: Konstantinos Michalakis

Copyright (C) 2018 Talib Amin Naqash et al. This is an open access article distributed under the Creative Commons Attribution License, which permits unrestricted use, distribution, and reproduction in any medium, provided the original work is properly cited.

\begin{abstract}
Ellis-van Creveld syndrome (EVC) is a very rare genetic disorder that affects various tissues of ectodermal and mesodermal origin; patients with EVC present with typical oral deficiencies. The affected individuals are quite young at the time of oral evaluation. It is, therefore, important that these individuals are diagnosed and receive dental treatment at an early age for their physiologic and psychosocial well-being. Albeit there are numerous articles penned on the EVC, the treatise from an oral perspective is inadequate, covering only oral exhibitions and the preventive treatments. This article reviews the literature and serves as the first disquisition for oral rehabilitation of an EVC patient utilizing surgical, orthodontic, restorative, and prosthodontic management.
\end{abstract}

\section{Introduction}

Ellis-van Creveld syndrome (EVC) is a rare autosomal recessive disorder with characteristic clinical manifestations, resulting from a genetic mutation in two genes, EVC1 and EVC2, mapping both in locus 16 on the short arm of chromosome 4 (4p16) in a head-to-head configuration $[1,2]$. EVC presents with a distinctive tetrad of disproportionate dwarfism, bilateral postaxial polydactyly, ectodermal dysplasia, and congenital heart malformations [3]. It is also known as chondroectodermal dysplasia and mesoectodermal dysplasia; dysplasia is an abnormality in form or development [4].

Pediatricians Richard W. B. Ellis of Edinburgh and Simon van Creveld of Amsterdam were the first to describe a case of EVC in 1940 [5]. The syndrome had been partially described previously in several reports, but work of Ellis and van Creveld defined it [6,7]. In literature, detailed description of clinical presentation in finite case series or single reports is found [3-13].

EVC presents with a characteristic tetrad of clinical manifestations [3]:
(1) Chondrodysplasia of the long, tubular bones resulting in disproportionate dwarfism, and an exceptionally long trunk is the most common clinical feature, producing a serious ossification defect [6]. The severity of short limbs increases from the proximal to the distal portions [6].

(2) Bilateral postaxial polydactyly of the hands, with the supernumerary finger, usually being on the ulnar side [6]. Fingers are sausage shaped with wide hands and feet [14].

(3) Hidrotic ectodermal dysplasia with dystrophic, small dysplastic nails, thin sparse hair, and oral manifestations [12].

(4) Congenital heart malformations in $50 \%$ to $60 \%$ of cases, the most common being a single atrium and a ventricular septal defect [6]. The associated cardiorespiratory problems are described as the primary cause of decreased life expectancy in these patients [15].

According to Winter and Geddes, oral manifestations in EVC are characteristic and remarkable [16]. The most 
common finding is the fusion of the anterior portion of the upper lip to the maxillary gingival margin, obliterating mucolabial fold, causing the upper lip to present a slightly $\mathrm{V}$-notch in the middle $[14,17]$. The anterior portion of the lower alveolar ridge is often jagged [7]. Multiple small accessory labiogingival frenula, serrated incisal edges, diastemas, teeth of abnormal form, enamel hypoplasia, and hypodontia are other features [3, 16]. Varela and Ramos stated that malocclusion is secondary to oral abnormalities and is of no specific type [18].

\section{Clinical Report}

A 15-year-old female was referred to the Department of Prosthetic Dentistry for evaluation and prosthetic dental treatment of congenitally absent maxillary lateral incisors and mandibular incisors (Figure 1). The patient was attending a regular school but had concerns about her esthetics.

Pregnancy and delivery were uneventful, and no exposure to radiation or drugs had occurred during pregnancy. At birth, however, the patient presented with short limbs, a long trunk, and polydactyly of hands. Medical history revealed that the patient has an atrial septal defect and was being planned for surgical closure. Psychomotor development was within the normal range. Extra oral examination showed that the patient has short limb dwarfism $(131 \mathrm{~cm})$, with a long trunk and weighed $37.1 \mathrm{~kg}$. Polydactyly of hands was observed with dysplastic and atrophic finger and toe nails (Figure 2). Hair was thin and sparse.

Intraoral examination showed absence of maxillary lateral incisors, mandibular central and lateral incisors, microdontia of the maxillary left canine, unilateral crossbite on the left side, partial end-to-end occlusal relationship on the right side, and alveolar ridge defect in the anterior mandible (Figure 3).

The examination of soft tissues showed presence of a large maxillary labial frenum attached to alveolar ridge causing obliteration of vestibule and midline diastema. Laterally, there were multiple small accessory labial frenula (Figure 3). The remaining oral mucosa was normal.

A panoramic radiograph confirmed agenesis of the maxillary lateral incisors, mandibular incisors, and all third molars (Figure 4).

Dental procedure that involved manipulation of gingival tissue or perforation of the oral mucosa was performed under proper antibiotic cover, as per revised guidelines from American Heart Association, to prevent infective (bacterial) endocarditis [19].

Treatment started with supragingival periodontal therapy for removal of plaque and calculus, and to improve oral health. It was followed by maxillary labial frenectomy and vestibular deepening, using electrosurgery. Electrocautery procedure offered minimal time consumption, bloodless field during the surgical procedure with no requirement of sutures, and absence of postoperative complications [20].

Following postoperative healing, orthodontic examination revealed that the patient had a unilateral crossbite on the left side. Cervical Vertebrae Maturation Index (CVMI),

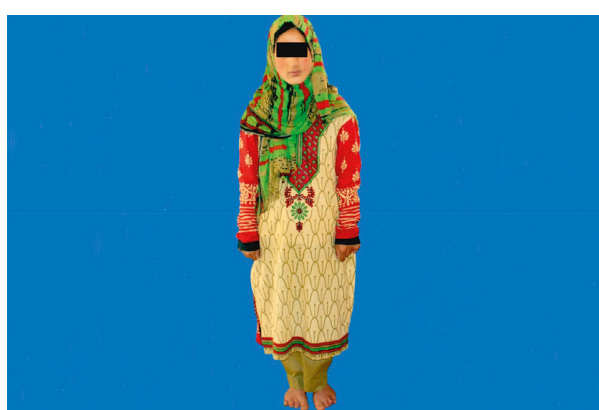

Figure 1: Patient with Ellis-van Creveld syndrome.

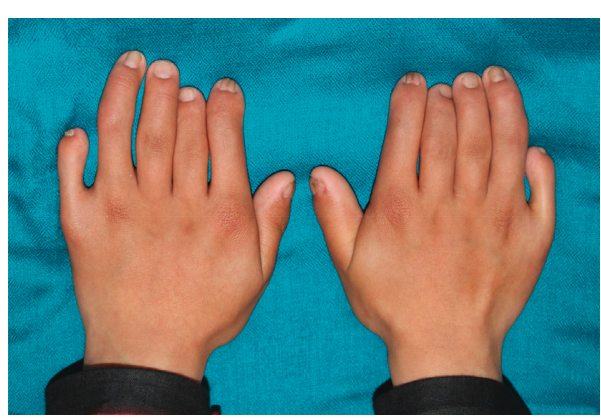

FIGURE 2: Hands showing polydactyly and hypoplastic nails.

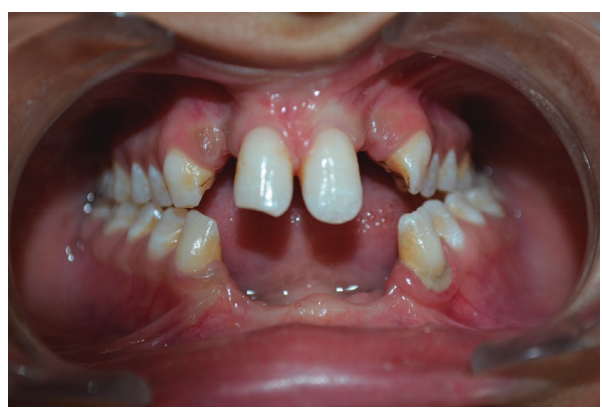

FIgURE 3: Absent maxillary lateral incisors and mandibular incisors, large maxillary labial frenum, multiple accessory labial frenula, midline diastema, mandibular anterior ridge defect, and crossbite.

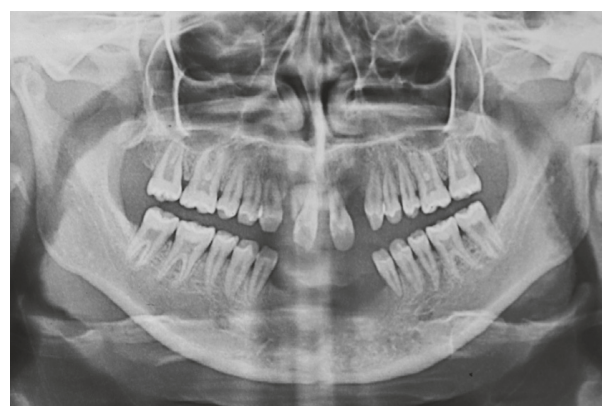

FIgURE 4: Panoramic radiograph showing agenesis of maxillary lateral incisors, mandibular incisors, and all 4 third molars.

using lateral cephalogram (Figure 5), depicted the patient to be in CVMI Stage V [21,22]. As such, the patient was put on Quad Helix, a slow maxillary expansion appliance, aimed at 


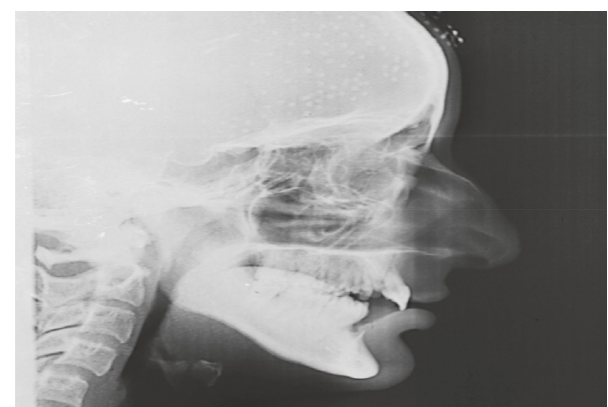

FIgURE 5: Lateral cephalogram.

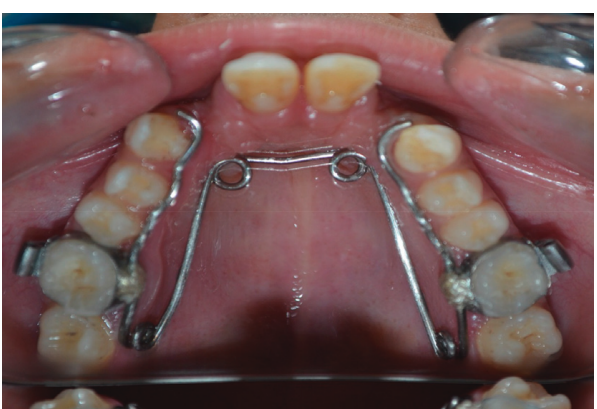

FIgURE 6: Quad helix cemented to maxillary molars.

dentoalveolar expansion of the arch on the left side and correction of partial end-to-end occlusion on the right side $[23,24]$. The appliance was fabricated from 36 mil stainless steel wire and was soldered with bands. Initial activation of $8 \mathrm{~mm}$ was done extraorally, and the bands were cemented with glass ionomer cement (Ketac Cem Glass Ionomer Cement, 3M) on maxillary molars (Figure 6). The patient was seen every four weeks for three months unless the appliance achieved $8 \mathrm{~mm}$ intraoral activation. After twelveweek treatment, crossbite was corrected and the appliance was removed. A retention appliance was placed for three months to prevent relapse.

After correction of crossbite, crown build-up, with glass ionomer cement (Vitremer, 3M), was done on the maxillary left canine, to correct microdontia.

Andrew's Bridge System was designed for rehabilitation of mandibular incisors on lower canines, keeping in view Seibert's class III ridge defect in the anterior mandible [25]. Andrew's Bridge System is a fixed removable prosthesis that is indicated in patients with large ridge defects. It provides maximum aesthetics, is hygienic, and has a good fit with minimal trauma to soft tissues or underlying bone at an economic price $[26,27]$. Bar and Clip attachments (PreciHorix, Ceka) were used to secure removable and fixed component (Figure 7).

Dental implants were planned for maxillary lateral incisors, but the patient was reluctant to undergo invasive treatment option, owing to her concerns about the cardiac defect. Therefore, six units metal ceramic fixed dental prosthesis (Ivoclar Vivadent) was fabricated in the maxillary arch, from canine to canine region, with maxillary canines and central incisors as abutments.
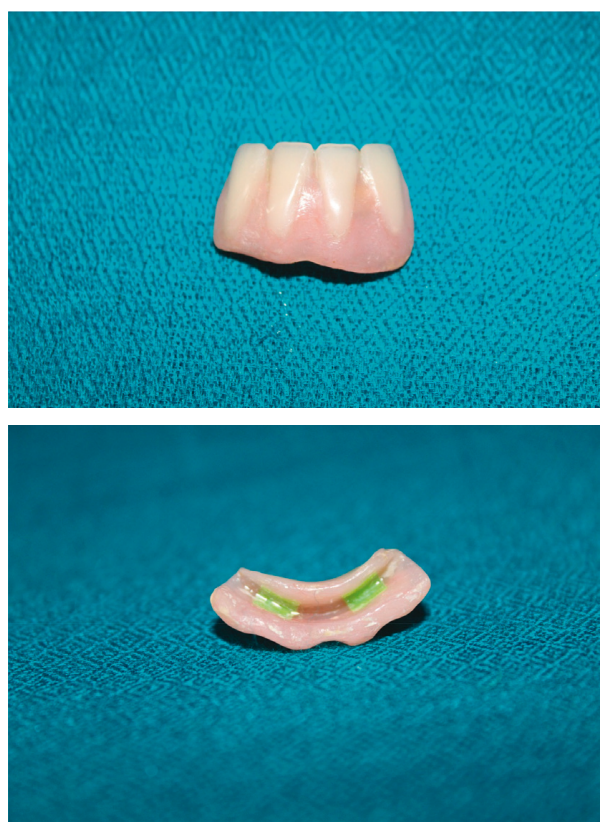

Figure 7: Andrew's removable component with Ceka Preciline attachments.

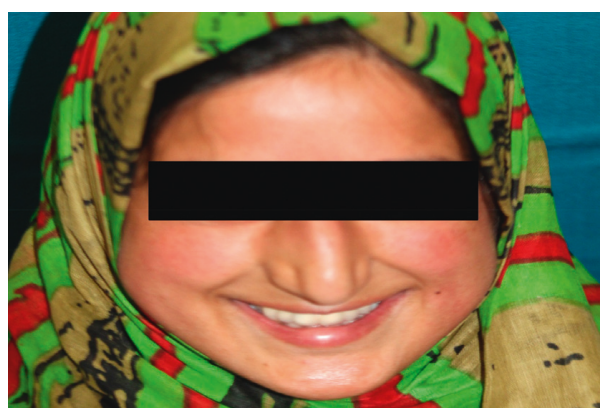

FIgURE 8: Clinical view after oral rehabilitation.

The patient was trained to properly insert and remove the removable prosthesis that was fabricated over the fixed component of Andrew's Bridge System, and proper oral hygiene instructions (including interdental brush) were given to the patient.

Follow-up was done for six months, and no complication after treatment was noted.

\section{Discussion}

The presentation of medically compromised and syndromic children in the dental office is a great challenge to oral health care providers [28]. Various syndromes are identified earlier in childhood and demand special attention right from the birth [28]. EVC is one of these syndromes with variable phenotype affecting multiple organs [11].

There is no definitive cure for EVC [29]. The management is multidisciplinary which involves several specialists: a cardiologist, a pediatrician, an orthopedician, a prosthodontist, an oral and maxillofacial surgeon, an orthodontist, and a periodontist [13, 30]. 
The approach to dental management will depend on each particular case [6]. Preventive measures include dietary counseling, plaque control, oral hygiene instructions, fluoride varnish application, or daily fluoride mouth rinses $[3,6,31]$.

To maintain space and to improve function, esthetics, and speech, removable or fixed dental prosthesis (considering age) is recommended [28]. Restoration of hypoplastic and decayed teeth is indicated to preserve tooth structure and to improve esthetics; taking into account possible presence of enlarged pulp chambers $[6,30]$. For soft tissue anomalies, surgical correction is advised [31]. Parental and child counseling is often required to treat psychological trauma due to compromised oral and medical health [28].

\section{Summary}

EVC is a rare autosomal recessive disorder with variable expression, diagnosed by its characteristic clinical manifestations. Dental and oral manifestations of EVC are definitive; dentist plays a vital role in its early diagnosis and treatment planning and to establish a differential diagnosis with other clinically similar entities. EVC has high mortality in early life due to cardiac and respiratory problems; those who survive require multidisciplinary treatment planning in terms of preventing oral diseases and providing rehabilitation. Early treatment can help the patient to prevent various problems and undue psychological trauma.

After completion of the treatment, esthetics, function and phonetics improved remarkably. The patient was happy and comfortable with the oral rehabilitation, and the post treatment esthetic outcome helped her to improve her quality of life (Figure 8).

\section{Conflicts of Interest}

The authors declare that there are no conflicts of interest regarding the publication of this paper.

\section{Acknowledgments}

The authors acknowledge the support of King Khalid University, Abha, Saudi Arabia, in preparation of this manuscript.

\section{References}

[1] M. H. Polymeropoulos, S. E. Ide, M. Wright et al., “The gene for Ellis van Creveld syndrome is located on chromosome 4p16," Genomics, vol. 35, no. 1, pp. 1-5, 1996.

[2] M. Galdzicka, S. Patnala, M. G. Hirshman et al., "A new gene, EVC2, is mutated in Ellis van Creveld syndrome," Molecular Genetics and Metabolism, vol. 77, no. 4, pp. 291-295, 2002.

[3] F. N. Hattab, O. M. Yassin, and I. S. Sasa, "Oral manifestations of Ellis-van Creveld syndrome. Report of 2 siblings with unusual dental anomalies," Journal of Clinical Pediatric Dentistry, vol. 22, pp. 159-165, 1998.

[4] D. Tahririan, A. Eshghi, P. Givehchian, and M. A. Tahririan, "Chondroectodermal dysplasia: a rare syndrome," Journal of Dentistry, vol. 11, pp. 361-364, 2014.

[5] R. W. Ellis and S. van Creveld, "A syndrome characterized by ectodermal dysplasia, polydactyly, chondrodysplasia and congenital morbus cordis. Report of 3 cases," Archives of Disease in Childhood, vol. 15, no. 82, pp. 65-84, 1940.

[6] A. Cahuana, C. Palma, W. Gonzales, and E. Gean, "Oral manifestations in Ellis-van Creveld syndrome: report of five cases," Pediatric Dentistry, vol. 26, no. 3, pp. 277-282, 2004.

[7] M. Atasu and S. Biren, "Ellis-van Creveld syndrome: dental, clinical, genetics and dermatoglyphic findings of a case," Journal of Clinical Pediatric Dentistry, vol. 24, pp. 141-145, 2000.

[8] V. A. Mckusick, J. A. Egeland, R. Eldridge, and D. E. Krusen, "Dwarfism in the Amish I. The Ellis van Creveld syndrome," Bulletin of the Johns Hopkins Hospital, vol. 115, pp. 306-336, 1964.

[9] M. L. Martinez Frias and A. Sanchez Cascos, "Ellis-van Creveld syndrome," Revista Clínica Española, vol. 133, no. 4, pp. 311-318, 1974.

[10] C. Stoll, B. Dott, M. P. Roth, and Y. Alembik, "Birth prevalence rates of skeletal dysplasia," Clinical Genetics, vol. 35, no. 2, pp. 88-92, 1989.

[11] G. Baujat and M. Le Merrer, "Ellis-van Creveld syndrome," Orphanet Journal of Rare Diseases, vol. 2, no. 1, p. 27, 2007.

[12] K. M. Zangwill, D. K. Boal, R. L. Ladda, J. M. Opitz, and J. F. Reynolds, "Dandy-Walker malformation in Ellis-van Creveld syndrome," American Journal of Medical Genetics, vol. 31, no. 1, pp. 123-129, 1998.

[13] J. A. Hanemann, B. C. de Carvalho, and E. C. Franco, "Oral manifestations in Ellis-van Creveld syndrome: report of a case and review of the literature," Journal of Oral and Maxillofacial Surgery, vol. 68, no. 2, pp. 456-460, 2010.

[14] C. Sergi, T. Voigtlander, S. Zoubaa et al., "Ellis-van Creveld syndrome: a generalized dysplasia of enchondral ossification," Pediatric Radiology, vol. 31, no. 4, pp. 289-293, 2001.

[15] D. Alves-Pereira, L. Berini-Aytes, and C. Gay-Escoda, "Ellisvan Creveld syndrome. Case report and literature review," Medicina Oral, Patologia Oral y Cirugía Bucal, vol. 14, no. 7, pp. E340-E343, 2009.

[16] G. B. Winter and M. Geddes, "Oral manifestations of chondroectodermal dysplasia (Ellis-van Creveld syndrome). Report of a case," British Dental Journal, vol. 122, pp. 103-107, 1967.

[17] P. Babaji, "Oral abnormalities in the Ellis-van Creveld syndrome," Indian Journal of Dental Research, vol. 21, no. 1, pp. 143-145, 2010.

[18] M. Varela and C. Ramos, "Chondroectodermal dysplasia (Ellis-van Creveld syndrome): a case report," European Journal of Orthodontics, vol. 18, no. 1, pp. 313-318, 1996.

[19] D. K. Lam, A. Jan, G. K. Sándor, C. M. Clokie, and American Heart Association, "Prevention of infective endocarditis: revised guidelines from the American Heart Association and the implications for dentists," Journal-Canadian Dental Association, vol. 74, no. 5, pp. 449-453, 2008.

[20] Devishree, S. K. Gujjari, and P. V. Shubhashini, "Frenectomy: a review with the reports of surgical techniques," Journal of Clinical and Diagnostic Research, vol. 6, no. 9, pp. 1587-1592, 2012.

[21] B. Hassel and A. G. Farman, "Skeletal maturation evaluation using cervical vertebrae," American Journal of Orthodontics and Dentofacial Orthopedics, vol. 107, no. 1, pp. 58-66, 1995.

[22] R. C. Santiago, L. F. de Miranda Costa, R. W. Vitral, M. R. Fraga, A. M. Bolognese, and L. C. Maia, "Cervical vertebral maturation as a biological indicator of skeletal maturity," Angle Orthodontist, vol. 82, no. 6, pp. 1123-1131, 2012. 
[23] S. J. Chaconas and J. A. de Alba y Levy, "Orthopedic and orthodontic applications of the quad-helix appliance," American Journal of Orthodontics, vol. 72, no. 4, pp. 422-428, 1977.

[24] R. W. Bench, "The quad helix appliance," Seminars in Orthodontics, vol. 4, no. 4, pp. 231-237, 1998.

[25] J. S. Seibert, "Reconstruction of deformed partially edentulous ridges using full thickness onlay grafts: part I-technique and wound healing," Compendium of Continuing Education in Dentistry, vol. 4, no. 5, pp. 437-453, 1983.

[26] R. J. Everhart and E. Cavazos Jr., "Evaluation of a fixed removable partial denture: Andrews Bridge System," Journal of Prosthetic Dentistry, vol. 50, no. 2, pp. 180-184, 1983.

[27] J. A. Andrews and W. F. Biggs, "The Andrews bar-and-sleeveretained bridge: a clinical report," Dentistry Today, vol. 18, no. 4, pp. 94-99, 1999.

[28] R. Kalaskar and A. R. Kalaskar, "Oral manifestations of Ellisvan Creveld syndrome," Contemporary Clinical Dentistry, vol. 3, no. 5, pp. S55-S59, 2012.

[29] R. Kamal, P. Dahiya, S. Kaur, R. Bhardwaj, and K. Chaudhary, "Ellis-van Creveld syndrome: a rare clinical entity," Journal of Oral and Maxillofacial Pathology, vol. 17, no. 1, pp. 132-135, 2013.

[30] T. Susami, T. Kuroda, H. Yoshimasu, and R. Suzuki, "Ellis-van Creveld syndrome: craniofacial morphology and multidisciplinary treatment," Cleft Palate-Craniofacial Journal, vol. 36, no. 4, pp. 345-352, 1999.

[31] M. L. Hunter and G. J. Roberts, "Oral and dental anomalies in Ellis-van Creveld syndrome (Chondroectodermal dysplasia): report of a case," International Journal of Paediatric Dentistry, vol. 8, no. 2, pp. 153-157, 1999. 


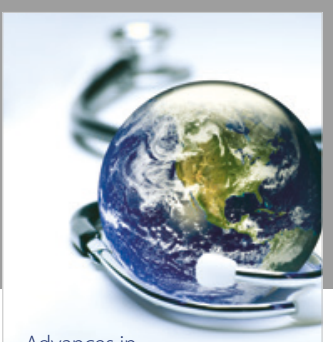

Advances in
Public Health

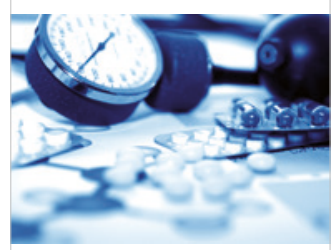

Case Reports in

Medicine

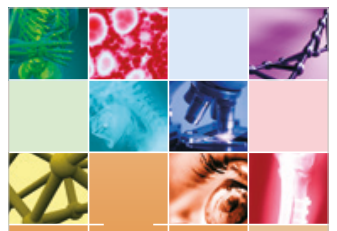

niernational Journal of

Biomaterials
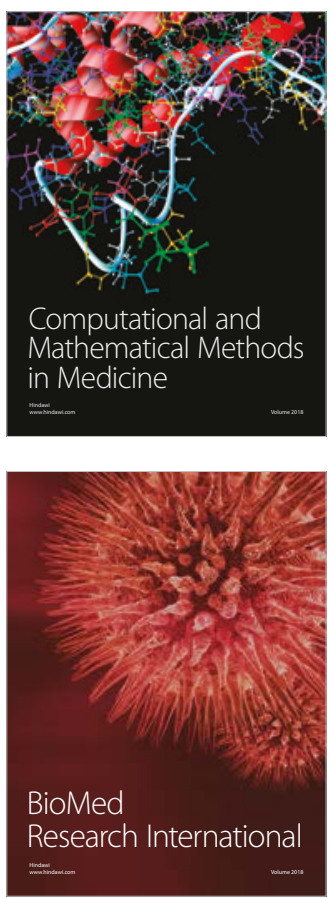

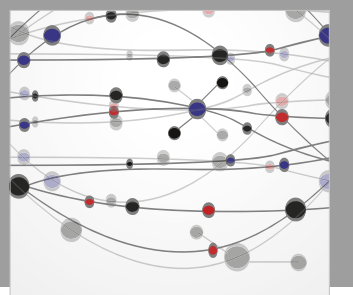

The Scientific World Journal Dentistry

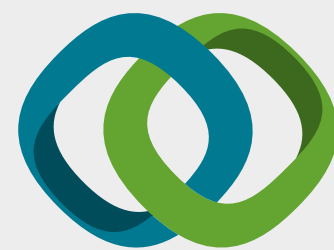

Hindawi

Submit your manuscripts at

www.hindawi.com
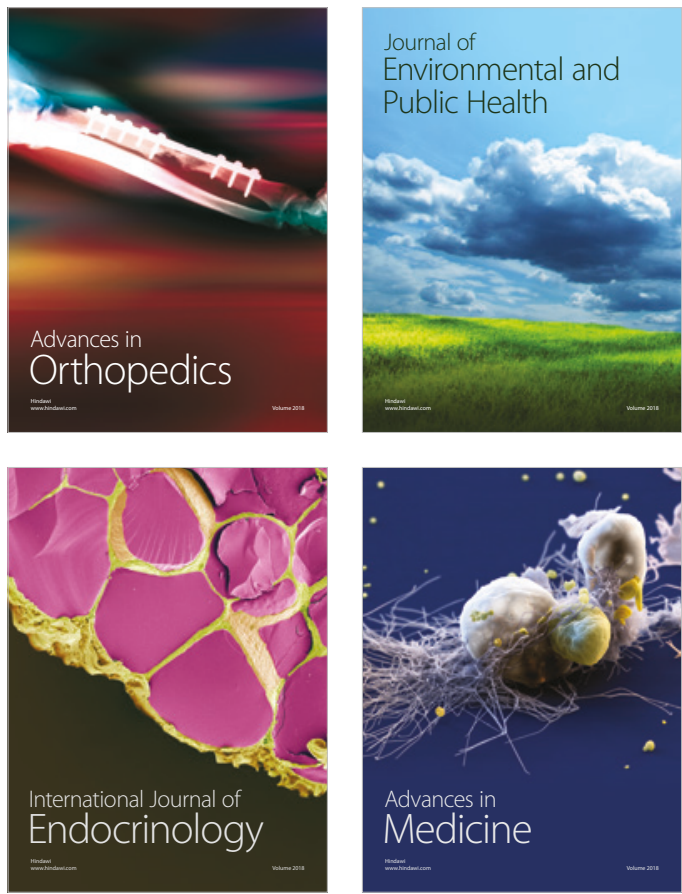
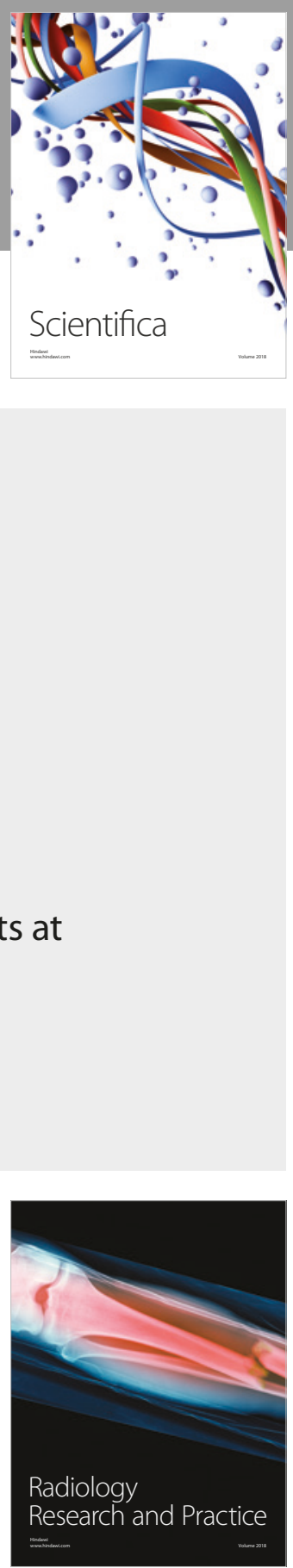

Scientifica

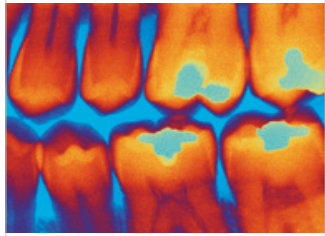

Case Reports in

Dentistry
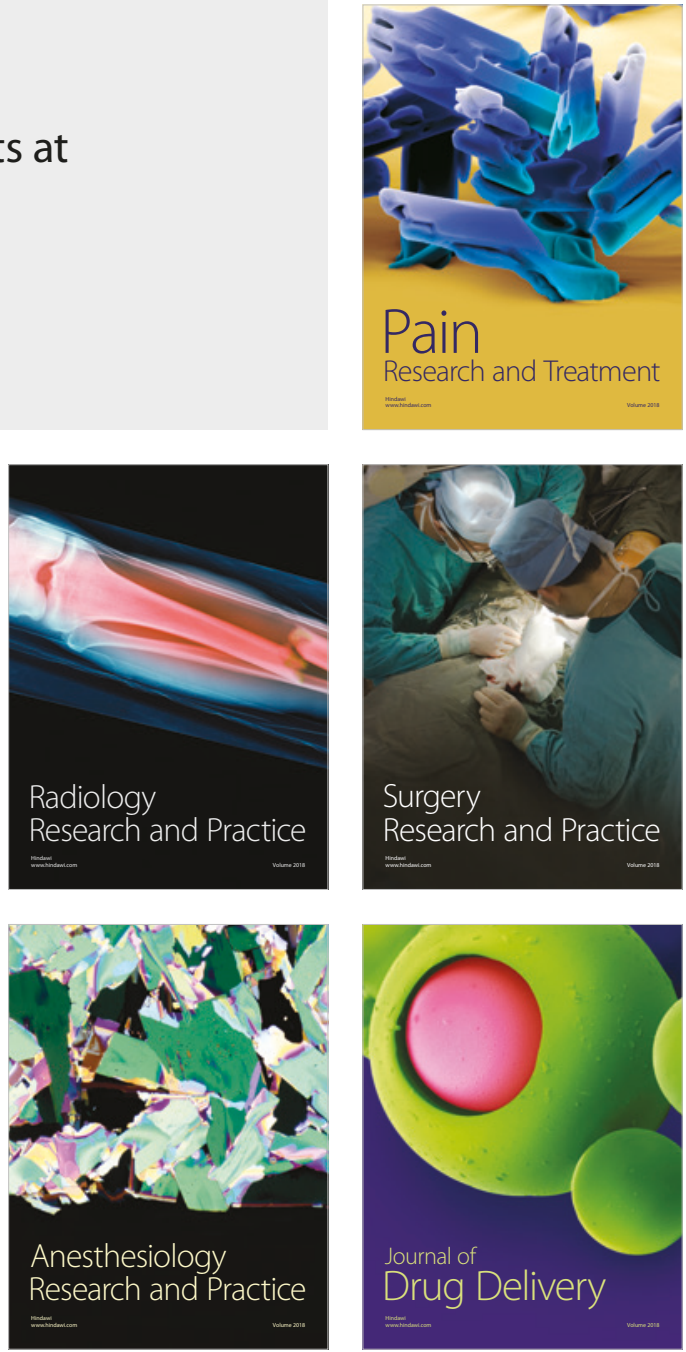